\title{
Movilidades geográficas y espirituales: cambio religioso y migración México-Estados Unidos
}

\author{
Olga Odgers Ortiz*
}

\begin{abstract}
In this paper we argue that migration to the United States is an important factor in the change of religious beliefs and practices of the migrating Mexican people. This also has an impact on their communities of origin. Starting from the analysis of statistical and ethnographic information, we conclude that the exposure to an environment with greater religious diversity, the distancing to traditional mechanisms of social control and the vulnerability due to their migrating condition contribute to the change mentioned above. This is manifested, among others, in the transnationalisation of traditional religious practices, in some conversion processes and the ethnic transformation of religious diversity.
\end{abstract}

Keywords: migration, religion, transnationalism, identity.

\section{Resumen}

En este trabajo sostenemos que la migración hacia los Estados Unidos constituye un importante factor de cambio en las creencias y prácticas religiosas de los mexicanos que se desplazan, incidiendo también en sus comunidades de origen. A partir del análisis de información estadística y etnográfica, concluimos que la exposición a un contexto de mayor diversidad religiosa, el distanciamiento de mecanismos tradicionales de control social y la vulnerabilidad de la condición del migrante contribuyen a dicho cambio, mismo que se manifiesta, entre otros aspectos, en la transnacionalización de prácticas religiosas tradicionales, algunos procesos de conversión, y en la etnicización de la representación de la diversidad religiosa.

Palabras clave: migración, religión, transnacionalismo, identidad.

* El Colegio de la Frontera Norte. Correo-e: odgers@dns.colef.mx. 


\section{Introducción $^{1}$}

Tanto el surgimiento de santos protectores de migrantes como la magnitud de las remesas colectivas destinadas a celebraciones religiosas, así como el papel que algunas asociaciones religiosas han desempeñado en la lucha por el respeto a los derechos humanos, o la coexistencia cada vez más visible de prácticas religiosas diversas en ciudades receptoras de migrantes, han puesto de manifiesto la necesidad de considerar al fenómeno religioso en los estudios sobre migración internacional. Simultáneamente, diversos estudios sobre las transformaciones recientes del campo religioso en países tan distintos como los Estados Unidos (Kurtz, 1995; Hirschman, 2004), Suecia (Hamberg, 1999) o México (Hernández Madrid, 2003; Odgers Ortiz y De la Torre, 2004) han destacado a la migración internacional como un factor de cambio de primera importancia.

Ese cruce de caminos pone en relieve la necesidad de continuar el análisis de la interrelación de esos campos, sistematizando los trabajos ya existentes y construyendo nuevas perspectivas de análisis.

Lo dicho antes no significa, evidentemente, que la relación que existe entre migración y cambio religioso sea un fenómeno nuevo, o que anteriormente no hubiera sido analizado. Lo que atestigua el rápido incremento de investigaciones sobre el tema es, ante todo, que las expresiones concretas de esa interrelación presentan características novedosas y van adquiriendo una magnitud y visibilidad inéditas.

Por ello, consideramos de la mayor relevancia continuar los análisis de las expresiones que esa interrelación adquiere el día de hoy en diversos contextos, para nutrir las reflexiones más amplias sobre las profundas transformaciones sociales y culturales derivadas de las nuevas movilidades, y sobre las formas y espacios que lo religioso va adquiriendo en las sociedades contemporáneas. El trabajo que aquí se presenta pretende ser una contribución a ese esfuerzo, partiendo de la experiencia concreta de los mexicanos que migran hacia los Estados Unidos. En particular, se pone el énfasis en los siguientes dos aspectos:

\footnotetext{
${ }^{1}$ Este trabajo fue elaborado en el marco del proyecto colectivo "Perfiles y tendencias del cambio religioso en México (1950-2000)", financiado por el Conacyt (C0242863).
} 
- La identificación de algunos de los principales elementos por los cuales la movilidad geográfica propicia el cambio religioso ${ }^{2}$ en sus diferentes dimensiones.

- La elaboración de un "inventario" de expresiones concretas en donde se constata el impacto de la experiencia de la migración de los mexicanos que viajan a los Estados Unidos en las transformaciones de las prácticas religiosas -tanto en México como entre los mexicanos radicados al norte de la frontera.

Las fuentes de las que partimos para la elaboración de este trabajo son principalmente tres. La primera y más importante es el trabajo etnográfico realizado en comunidades tanto de origen como de destino: se trata de Alto Lucero (Veracruz) y Chinantla (Puebla), en México, y de Chula Vista, California, localidad fronteriza de los Estados Unidos con una importante presencia de migrantes mexicanos. La información obtenida en dichas comunidades se complementa con algunas entrevistas realizadas en Nueva York a migrantes poblanos originarios de Chinantla. ${ }^{3}$

La segunda fuente de información es de corte estadístico. La constituyen, en primera instancia, los censos nacionales de población de México, que permiten obtener valiosas informaciones relativas tanto a la migración hacia los Estados Unidos como a las tendencias generales del cambio religioso, en los niveles nacional, regional y municipal, para las ultimas décadas. Esa información se complementa con los datos estadísticos disponibles relativos a la distribución de las diferentes adscripciones religiosas en los Estados Unidos. ${ }^{4}$

2 Como se verá mas adelante, por cambio religioso entendemos, además de los eventuales procesos de conversión, la transformación de prácticas religiosas tradicionales y del sentido asociado con las mismas.

${ }^{3}$ En Chinantla, Puebla, se realizaron dos estancias de trabajo de campo en enero de 2002 y enero de 2003. En Alto Lucero, Veracruz, se realizó una primera visita en la Semana Santa de 2002, y una segunda estancia en enero de 2003. En Chula Vista se realizó una primera estancia en el verano de 1996; se realizaron entrevistas complementarias en 1999, 2002, 2003 y 2005.

${ }^{4}$ Consideramos principalmente los resultados disponibles del proyecto "American Religious Data Archive" (que pueden ser consultados en www.thearda.com) y del proyecto "Hispanic Churches in American Public Life", presentados en Interim Reports, vol. 2003, 2a ed. marzo 2003 (disponible en: www.nd.edu/research/publications.htm). 
Finalmente, consideramos como una tercera fuente los importantes y cada vez más numerosos trabajos que diversos investigadores han publicado recientemente sobre este tema. ${ }^{5}$

Creemos que con la combinación de esas tres fuentes es posible tener un panorama amplio de la forma como la migración internacional ha incidido en la transformación de la religiosidad de los mexicanos dentro y fuera de sus comunidades de origen.

En el primer apartado presentamos algunos elementos asociados con la migración internacional que contribuyen a conformar un contexto favorable para el cambio religioso. En particular, nos referiremos a la exposición a un contexto de mayor diversidad, al distanciamiento de mecanismos de control social tradicionales, a la vulnerabilidad asociada con la condición migratoria, y al proceso de redefinición de referentes identitarios asociados con los procesos de integración a las sociedades de destino.

En un segundo apartado exponemos, a manera de "inventario", algunas de las expresiones concretas que adopta la relación religión-migración, clasificándolas en tres grandes grupos: los procesos de conversión, la transnacionalización de las prácticas religiosas, y la etnicización de la percepción de la diversidad religiosa.

Concluimos este trabajo con algunas reflexiones teóricas sobre lo que consideramos que podrían ser nuevas estrategias de análisis en este campo.

\section{La migración internacional como factor de cambio religioso}

Como parte de su herencia colonial, México ha sido un país tradicionalmente católico desde los primeros años de vida independiente. Y aunque las elites protestantes pudieron haber jugado un papel importante en determinados episodios de la historia nacional (Bastian, 1994), la diversidad religiosa mexicana a lo largo de la historia había estado dada principalmente por las diferentes expresiones de la religiosidad popular al interior de un catolicismo sincrético, y sólo marginalmente por la adscripción a otras religiones.

Sin embargo, aunque hoy en día la mayoría de los mexicanos sigue profesando la fe católica, durante las últimas décadas ha habido importantes transformaciones en el panorama religioso de este país. Una de las expresiones más claras de esos cambios,

${ }^{5}$ Debido a que la bibliografía sobre el tema es cada vez más abundante, a lo largo de este texto citamos únicamente algunos de los trabajos que consideramos especialmente relevantes. 
aunque no la única, se ve reflejada en el descenso, lento pero sostenido, en el porcentaje de población católica registrado en los censos nacionales de población. ${ }^{6}$ Como se puede observar en la gráfica I, el censo del año 2000 reportó $88 \%$ de población católica, lo que significa un descenso de más de 10 puntos porcentuales durante los últimos cincuenta años.

\section{Gráfica I \\ México: población católica y no católica (1950-2000)}

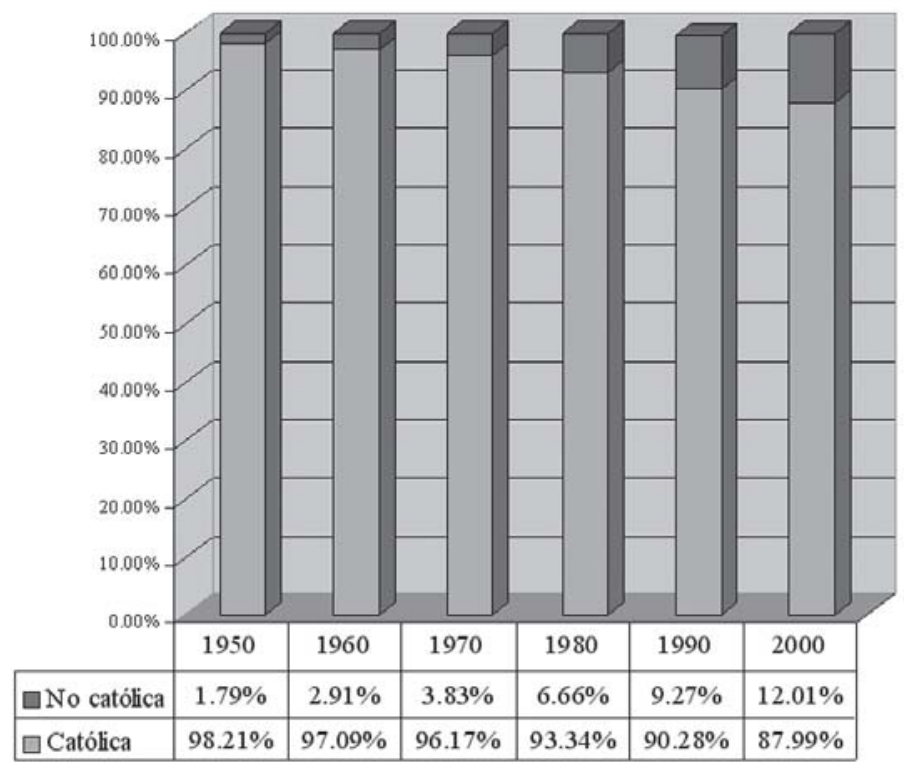

Fuente: Elaboración propia con base en INEGI, XII Censo General de Población y Vivienda 2000.

La disminución proporcional del catolicismo corresponde tanto al aumento porcentual de quienes no profesan ninguna religión, como al crecimiento de otras religiones, principalmente "protestantes y evangélicas" y "bíblicas no evangélicas".?

${ }^{6}$ Salvo indicación contraria, todas las cifras de adscripción religiosa en México provienen de los censos nacionales de población.

${ }^{7}$ Retomamos la clasificación empleada en el XII Censo General de Población y Vivienda 2000, según la cual la categoría “protestantes y evangélicas” incluye las subcategorías siguientes: protestantismo histórico, pentecostales y neopentecostales, Iglesia del Dios Vivo, Columna y Apoyo de la Verdad, Luz del Mundo, y otras evangélicas. La categoría "bíblicas no evangélicas" está constituida por Testigos de Jehová, Adventistas del Séptimo Día, e Iglesia de los Santos de los Últimos Días (mormones). Finalmente, para la elaboración de la gráfica in integramos la categoría "judaica" al rubro "otras religiones" debido a que su presencia numérica es marginal (0.053\%); asimismo, se omitió el $0.864 \%$ correspondiente al rubro "no especificado". 


\section{Gráfica II \\ México: Distribución porcentual de población no católica (2000)}

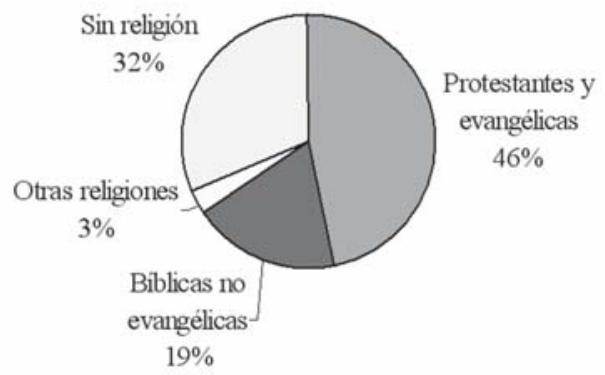

$\square$ Protestantes y evangélicas
$\square$ Biblicas no evangélicas
$\square$ Otras religiones
$\square$ Sin religión

Fuente: Elaboración propia con base en INEGI, XII Censo General de Población y Vivienda 2000.

Hay, además, otros cambios importantes en el panorama religioso mexicano que las cifras no reflejan. Entre ellos, podemos señalar la transformación de la relación Estado-Iglesia, la modificación de algunas prácticas religiosas tradicionales, la institucionalización de otras nuevas, la "exportación" de expresiones de la religiosidad popular mexicana a las comunidades de mexicanos establecidos en los Estados Unidos, etc. Aunque resulte imposible detallar la magnitud de ese otro tipo de transformaciones, sabemos que su impacto en la sociedad mexicana $-\mathrm{y}$ en las comunidades mexicanas radicadas en el extranjero- es de gran relevancia.

Ahora bien, las modificaciones arriba señaladas responden a un sinnúmero de factores, que pueden ser de carácter local, regional o global, internos o externos a las instituciones, políticos, culturales, etc. Por ello, más que identificar las “causas" del cambio -mismo que, por otra parte, es natural a todas las sociedades- se pretende identificar factores que contribuyen a la conformación de contextos favorables a tales transformaciones.

Entre los factores señalados, los flujos migratorios ocupan un importante lugar, en lo que respecta tanto a las comunidades de origen (véase, por ejemplo, Hernández Madrid, 2000) como a las de destino (por ejemplo, Warner y Wittner, 1998). En particular en el caso de México, debido a la magnitud de la movilidad hacia los Estados Unidos -y de regreso- consideramos que este factor resulta de primera importancia. ${ }^{8}$ Es por ello que, sin desestimar la

${ }^{8}$ Según estimaciones del Consejo Nacional de Población, en el año 2000 la población nacida en México que vivía en los Estados Unidos era de aproximadamente 8.8 millones. Asimismo, se estima que más de $18 \%$ de los hogares mexicanos tenían "familiares directos con algún tipo de experiencia migratoria en Estados Unidos” (Tuirán et al., 2002). 
importancia del carácter multicausal en las transformaciones del campo religioso, este trabajo se centra en el análisis del impacto de la migración internacional en la conformación de contextos favorables a dichos cambios.

Así, a partir de la evidencia empírica, y retomando los hallazgos reportados por diversos investigadores, consideramos que los cuatro aspectos principales que hacen de la experiencia migratoria un factor de cambio en el campo religioso son: una mayor exposición a la diversidad religiosa, el distanciamiento de mecanismos tradicionales de control social, la vulnerabilidad asociada con la condición migratoria, y el proceso de redefinición de referentes identitarios, de normas y valores, que exige la incorporación a la sociedad receptora.

Antes de detallar cada uno de esos elementos, conviene insistir en que, al identificar a la migración internacional como factor de cambio, no estamos considerando que la experiencia migratoria conduzca a quienes se desplazan a procesos de conversión religiosa o de cambio de adscripción. El cambio al que nos referimos es a la vez más profundo y menos evidente, y puede darse al interior mismo de una denominación -como podría ser el catolicismo. Como se verá mas adelante, el cambio puede identificarse en la forma concreta en que se realiza -o deja de realizarla práctica religiosa, en el sentido que se atribuye a la misma, o incluso en la relación que el propio individuo redefine respecto a las diversas instituciones religiosas.

\subsection{Mayor exposición a la diversidad religiosa}

A pesar de que durante las últimas décadas las afiliaciones religiosas de los mexicanos han adquirido progresivamente un carácter más plural, el catolicismo sigue siendo, con mucho, la adscripción religiosa mayoritaria y el sistema de creencias hegemónico en este país, en donde $88 \%$ de la población sigue autoidentificándose como "católico". Esa hegemonía del catolicismo es aún más acentuada en las regiones que tradicionalmente han tenido una mayor participación en los flujos migratorios: en Zacatecas, Michoacán y Guanajuato -los tres estados que presentan un mayor índice de intensidad migratoria-, ${ }^{9}$ el porcentaje

\footnotetext{
${ }^{9}$ En este trabajo retomamos el "índice de intensidad migratoria" propuesto por el Consejo Nacional de Población y elaborado a partir de la información censal del año 2000. Ese índice tiene la virtud de considerar, además de los desplazamientos como tales, el impacto que dichos desplazamientos tienen en los hogares de las comunidades
} 


\section{Gráfica III \\ Diversidad religiosa e intensidad migratoria (entidades federativas, 2000)}

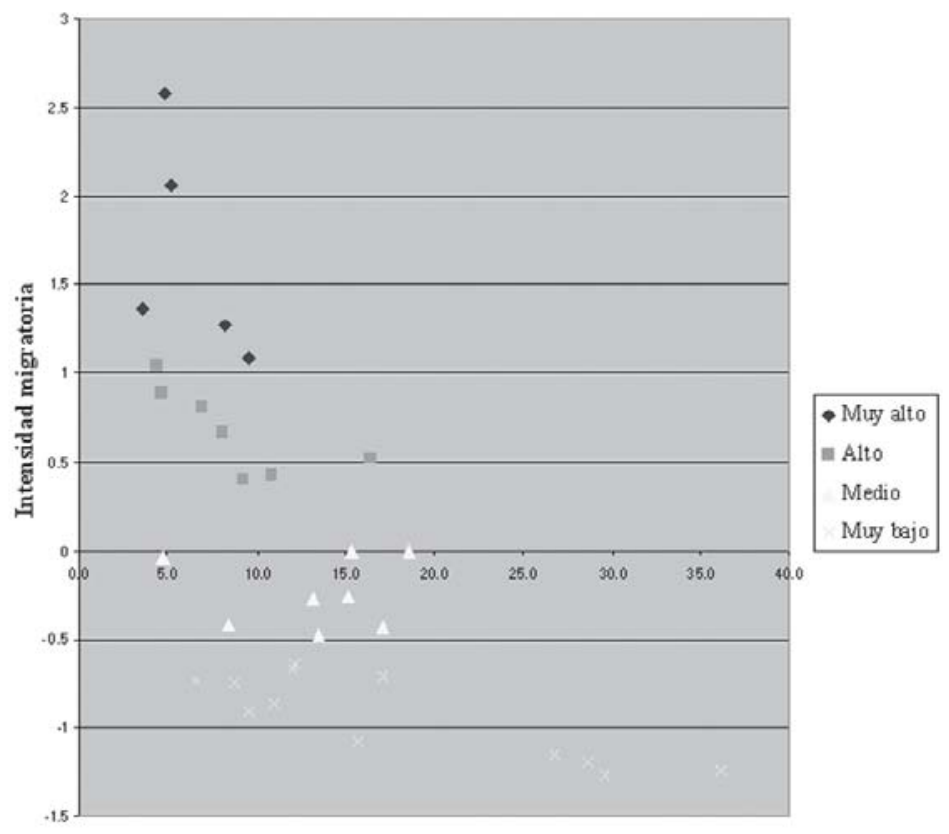

Pobl ación no católica

Fuente: Elaboración propia con base en INEGI, XII Censo Nacional de Población y Vivienda 2000; y Tuirán et al. (2002).

de población no católica es notablemente inferior a la media nacional $(4.9,5.2$ y 3.6 , respectivamente).

Esa marcada hegemonía del catolicismo en las comunidades de origen contrasta fuertemente con la diversidad religiosa prevaleciente en los lugares de destino: en Nuevo México, California, Texas y Arizona -los cuatro estados que concentran mayores porcentajes de población hispana-, el porcentaje de población católica alcanza apenas $36.9,29.8,21$ y 19 , respectivamente. ${ }^{10}$

de origen, al integrar variables tales como la recepción de remesas o la proporción de hogares con emigrantes. La metodología empleada para construir ese índice puede ser consultada en Tuirán et. al (2002).

${ }^{10}$ Los porcentajes presentados corresponden a la información disponible en www.thearda.com (consultado el 2 de mayo de 2005). Otra encuesta que proporciona información relativa a la adscripción religiosa en los Estados Unidos es la American Religious Identification Survey, misma que puede ser consultada en http:// www.gc.cuny.edu/studies/key-findings.htm. Como es natural, las cifras presentadas por una y otra fuentes no son idénticas). 
El contacto con la diversidad religiosa adquiere su expresión concreta en la interacción con vecinos, compañeros de trabajo, empleadores o compañeros de estudios, y por lo general no se reduce a las opciones religiosas evangélicas y protestantes. Así, por ejemplo, los mexicanos a quienes entrevistamos en Chula Vista, California, señalaron tener amistades de diversos orígenes (principalmente filipinos, coreanos, griegos, libaneses y japoneses), y la mayoría de ellos señalaron también haber asistido por lo menos en una ocasión a un oficio religioso de una religión diferente a la propia; en la mayoría de los casos, debido al deseo de acompañar a familiares o amigos en algún acontecimiento significativo para ellos (bautismos y matrimonios, principalmente). ${ }^{11}$

La confrontación con un contexto de acentuada diversidad religiosa -misma que adquiere gran visibilidad en el espacio público- en algunos casos puede resultar desconcertante para los migrantes mexicanos habituados a considerar al catolicismo, y al conjunto de normas y valores derivados de la cultura católica, como prácticas de carácter universal. Así, por ejemplo, Horacio, quien reside en Chula Vista, California, muestra su asombro ante la diversidad religiosa cuando sostiene: "No es posible que haya tantas religiones [...] religiones no se les puede llamar [...] sólo son cuatro, porque también son cuatro los puntos [cardinales] del mundo, pero que en un solo país haya tantas religiones no es posible" (Horacio, entrevistado en Chula Vista, California, 1999). ${ }^{12}$

Si bien es cierto que la simple exposición a la diversidad religiosa no necesariamente deriva en procesos de conversión, también es evidente que un contexto diverso resulta favorable para la reflexión crítica sobre los sistemas de creencias interiorizados durante el proceso de socialización primaria. Como veremos en los siguientes apartados, el contacto con un contexto religioso diferente será un factor de cambio religioso importante, pero tales cambios no necesariamente cristalizarán en procesos de conversión religiosa.

Conviene aclarar que, debido a que el Censo de los Estados Unidos no integra ninguna pregunta relativa a la adscripción religiosa, los datos disponibles provienen de encuestas nacionales. La información no es estrictamente comparable con la que proveen los censos mexicanos, pero puede servir de manera indicativa.

${ }^{11}$ De las 46 personas entrevistadas en Chula Vista en 1996, 44 declararon haber asistido a celebraciones religiosas no católicas.

${ }^{12}$ Con la finalidad de respetar la confidencialidad de los datos provenientes de las entrevistas, todos los nombres asentados aquí son ficticios, no así la fecha y lugar de la entrevista. 


\subsection{El distanciamiento de mecanismos tradicionales de control social}

La inquietud que produce la confrontación con un contexto de marcada pluralidad religiosa motiva un proceso de reelaboración de referentes de identidad en el que la subjetividad y la reflexividad son profundamente movilizadas. Ese proceso, además, tendrá lugar en un contexto en donde los mecanismos tradicionales de control social -desde los más sutiles hasta los más explícitos- pierden eficacia o dejan de ser operativos.

Un ejemplo de ello es el de aquellos hombres jóvenes que se integran a los mercados laborales transnacionales en jornadas extenuantes y que, a diferencia de lo que harían en sus comunidades de origen, emplean el limitado tiempo libre del que disponen en actividades diferentes de las prácticas religiosas tradicionales, como ir a misa. Es el caso de Eduardo, originario de Alto Lucero, Veracruz, quien menciona que en Dallas nunca va a la iglesia, pues de lunes a sábado procura trabajar la mayor cantidad de horas posible (siempre que se presenta la oportunidad de trabajar "over-time" la aprovecha, por ser horas mejor pagadas, por lo que con frecuencia trabaja 12 horas al día), de manera que el domingo prefiere realizar las tareas domésticas indispensables y descansar. En el pueblo, en cambio, suele ir a misa "cuando menos los domingos", "para agradecer a Dios que vivió uno un día mas", y también porque "a fuerzas tiene uno que acompañar a la familia", "se vería mal que uno no fuera" y "si no luego la gente anda diciendo" (entrevista realizada en Alto Lucero, Veracruz, enero de 2003).

Miguel Hernández, quien analiza el caso de mujeres migrantes que a su regreso de los Estados Unidos se convirtieron en Testigos de Jehová, señala que

[...] los que van a Estados Unidos tienen mayores oportunidades de conocer otras religiones, de moverse en ambientes donde pueden leer la Biblia sin los condicionamientos y tabúes que imperan en sus terruños, pero además lo pueden hacer en lugares donde el gran número de población y actividades garantizan el anonimato y la disolución de la vigilancia o censura por interactuar con los 'otros' (Hernández Madrid, 2000).

Eso no significa, claro está, que en el nuevo contexto no existan otros mecanismos de control -especialmente cuando el desplazamiento tiene lugar dentro de redes migratorias sólidamente 
estructuradas-, pero esos nuevos mecanismos corresponden, precisamente, a una nueva lectura de la posición de las creencias “propias" y a una diferente percepción de la diversidad religiosa en ese contexto de marcada pluralidad.

\subsection{La vulnerabilidad asociada con la condición migratoria}

Al llegar a los Estados Unidos, el nuevo migrante tendrá que adquirir los elementos materiales y la información necesaria para adaptarse a su nuevo contexto de vida. Es por ello que en los primeros días, semanas e incluso meses posteriores a su desplazamiento, quienes migran son extremadamente dependientes de terceras personas para sobrevivir. A partir de las entrevistas realizadas a quienes se encontraban en esa situación, pudimos comprobar que los recién llegados experimentan una profunda sensación de soledad y vulnerabilidad, que resulta particularmente angustiosa para quienes no tienen la fortuna de desplazarse con la ayuda de redes de familiares, paisanos o amigos. En esos casos -más aún cuando se trata de migrantes indocumentados-, las instancias a las que los migrantes pueden recurrir en la búsqueda de soluciones a sus necesidades más apremiantes son extremadamente escasas. Dentro de ese estrecho universo, las asociaciones religiosas de diversas denominaciones ocupan un importante lugar. Así pues, la vulnerabilidad derivada de la condición migratoria es en ocasiones la causa y el contexto en el que los migrantes entran en contacto por primera vez con otras opciones religiosas. Y ello no necesariamente redundará en procesos de conversión, pero sí contribuirá a modelar una nueva representación de la alteridad religiosa, y a construir una nueva relación con el "otro". ${ }^{13}$

${ }^{13}$ A manera de ejemplo podemos citar el caso de Horacio, padre de familia de 42 años que decidió emigrar a los Estados Unidos cuando cerró el laboratorio clínico en donde trabajaba en la Ciudad de México. Horacio llegó a Chula Vista a residir en la casa de una prima de su esposa que pertenecía a una iglesia "cristiana". Además de brindarle alojamiento, los miembros de la iglesia lo ayudaron a obtener los documentos necesarios para regularizar su situación migratoria. Él acompañaba a los familiares de su esposa cada domingo al templo porque de cualquier forma él no tenía nada mejor que hacer: se sentía solo, y como no tenía documentos migratorios, no se atrevía a salir solo a la calle. Posteriormente, los miembros de esa comunidad religiosa lo ayudaron a obtener empleo en una tienda departamental. "Afortunadamente -narra Horacio- yo tenía que trabajar los domingos, y por consiguiente no necesitaba inventar pretextos para dejar de acompañarlos a la iglesia”. Comenzó a hacer amigos entre sus compañeros de trabajo y pudo ir alejándose del grupo. De la gente de la iglesia nunca recibió ningún reproche, aunque sí le solicitaron un tiempo más tarde que le ayudara a un nuevo miembro de la comunidad a conseguir empleo en la tienda en donde trabajaba. "Yo me 


\subsection{La redefinición de referentes identitarios y la búsqueda de nuevos sentidos}

Si consideramos que los sistemas religiosos están conformados por las "construcciones imaginarias mediante las que la sociedad, los grupos en esta sociedad y los individuos en estos grupos tratan de conferir un sentido a su experiencia cotidiana y representarse su origen y su porvenir" (Hervieu-Léger, 1996), resulta evidente que una transformación profunda en las condiciones de esa misma experiencia cotidiana exigirá una transformación de las propias construcciones imaginarias que conforman los sistemas religiosos. Ese fenómeno ha sido ampliamente estudiado desde la perspectiva de la "larga duración", al analizarse las implicaciones que "la afirmación del individuo, el progreso de la racionalización y la diferenciación de las instituciones" (Hervieu-Léger, 1996) han tenido sobre los sistemas religiosos en las sociedades modernas. Pero también puede observarse en la escala del individuo, para el cual la transformación profunda y acelerada en las condiciones concretas de la experiencia cotidiana exige la readecuación de los sistemas de creencias a partir de los cuales ha dado sentido a su existencia. El viaje al norte constituye entonces la ocasión para entrar en contacto con otras opciones religiosas, pero además, ese acercamiento se produce precisamente en un momento en la vida de los individuos en el que se encuentran inmersos en la búsqueda de nuevas explicaciones, de nuevos sentidos para su, también nueva, experiencia de vida.

El extraordinario contraste entre las condiciones de vida concretas en las que se encuentra el recién llegado, que son con frecuencia aún más precarias que las que dejó al partir -especialmente para quienes no disponen de documentos migratorios y viven bajo el estigma de la clandestinidad-, y el nuevo horizonte de expectativas -con frecuencia ilusorias- que se abre ante él, configura un contexto de tensión para el que los individuos deberán encontrar -o construir- nuevas justificaciones. Se trata, sin duda, de un caso extremo de lo que Hervieu-Léger describe para el conjunto de las sociedades modernas:

La oposición entre las contradicciones del presente y el horizonte de una realización futura crea, en el corazón de la modernidad, un espa-

sentí obligado a hacerlo. Realmente no tenía opción, pero lo hice con gusto porque pensé que así les pagaba el favor que les debía, y en el futuro no tendrían nada que echarme en cara" (entrevista realizada en Chula Vista, 1999). 
cio de expectativas en el que se desarrollan [...] nuevas formas de religiosidad que permitan superar esta tensión: representaciones nuevas de lo sagrado o apropiaciones renovadas de tradiciones religiosas históricas (Hervieu-Léger, 1999).

Por lo anterior no es sorprendente el hecho de que, en los discursos sobre la propia identidad y la relación con la alteridad, los migrantes mexicanos a quienes entrevistamos en Chula Vista, California, hicieran referencia constantemente a las afiliaciones religiosas, ya sea que éstas fueran invocadas en su aspecto moral (como sistema de normas y valores), cultural (en referencia a las prácticas religiosas específicas), o explícitamente como afiliación a un "linaje creyente" 14 determinado, como en el caso de quienes se identifican entre paisanos por ser hijos de "Nuestra madre la Virgen de Guadalupe”.

Así pues, la experiencia migratoria en sí misma, por las profundas implicaciones que conlleva en la experiencia de vida cotidiana de quienes se desplazan, configura también un contexto favorable al cambio religioso -aunque no necesariamente a la conversión- debido a que los sistemas de creencias son fuertemente movilizados y reinterpretados en la búsqueda de nuevos sentidos para la existencia propia, para la representación del origen, y para la construcción de esperanzas para el porvenir.

En suma, consideramos que la exposición a la diversidad religiosa, el distanciamiento de mecanismos tradicionales de control social, la vulnerabilidad del migrante y el proceso de redefinición de referentes identitarios, sin ser los únicos elementos que permiten identificar a la migración como un factor de cambio religioso, constituyen pistas de análisis del impacto que, en contextos específicos, imprime la movilidad geográfica a la esfera de las creencias y las prácticas religiosas.

A continuación presentamos lo que hemos identificado como algunas de las transformaciones que la migración hacia los Estados Unidos ha impreso en las afiliaciones y las prácticas religiosas, así como el sentido que los migrantes mexicanos atribuyen a ellas.

\section{Migración y conversión}

Cuando las hijas de la señora Fabiola -originarias de Chinantlaemigraron a los Estados Unidos, entraron en contacto con mexicanos Testigos de Jehová, y después de algún tiempo ellas tam-

${ }^{14}$ Retomo el término de Danièle Hervieu-Léger (1993). 
bién "se bautizaron". Al conocer la decisión de sus hijas, la señora Fabiola -quien permanecía en el pueblo- comenzó a recibir en su casa a los Testigos de Jehová del pueblo vecino, quienes desde hacía décadas llamaban sin éxito a su puerta. Finalmente ella también se integró a la congregación (entrevista realizada en Chinantla, Puebla, enero de 2003).

La historia de la conversión de la señora Fabiola y sus hijas es semejante a tantas otras que pueden encontrarse en las regiones expulsoras de migrantes. Al igual que otros casos que han sido analizados en diversos trabajos, ${ }^{15}$ el caso de la señora Fabiola muestra con claridad que la experiencia de la migración puede ser un elemento fundamental para comprender los procesos de conversión de los mexicanos que migran al norte e incluso el de algunos de sus familiares que nunca cruzaron la frontera. En relatos como el de la señora Fabiola y sus hijas, los procesos de conversión pueden ser leídos como la búsqueda de nuevos sistemas portadores de sentido que respondan a experiencias de vida también inéditas para los individuos.

Desde una perspectiva muy diferente, la relación entre migración internacional y cambio religioso también se ve reflejada en la preocupación que el contacto con la sociedad estadounidense ha suscitado en diversos sectores de la jerarquía católica. Así, por ejemplo, Víctor Espinoza señala que ya desde la segunda década del siglo $\mathrm{xx}$,

[...] a la jerarquía de la Iglesia católica de la zona [Los Altos de Jalisco] le preocuparon tres problemas que consideraba ligados a la migración: la desintegración familiar causada por la falta del varón en la casa, la pérdida de los valores morales y el peligro de que abandonaran la religión católica y cayeran en las garras de alguna iglesia protestante (Espinoza, 1999).

Esos "peligros" motivaron a algunos sacerdotes a acompañar a los migrantes hacia el norte ${ }^{16}$ para protegerlos de "las trampas de otros grupos religiosos que vendían a Jesús 'por treinta monedas'” (Espinoza, 1999). La preocupación se magnificaba en la medida en que la migración adquiría patrones cada vez más "circulares”, pues la migración entonces no solamente amenazaba a quienes partían, sino muy especialmente a quienes permanecían en el terruño creando y recreando la emblemática figura del mi-

${ }^{15}$ Véase, por ejemplo, el excelente trabajo de Miguel Hernández Madrid (2000).

${ }^{16}$ Entrevista realizada por Ariel Mojica, en Tijuana (2005), a migrantes que participaron en el Programa Bracero en la primera mitad del siglo xx. 
grante exitoso. Los hijos pródigos, tan queridos y esperados por familiares y amigos, que regresaban cargados de dólares, nuevas costumbres e ideas extrañas, constituían la verdadera amenaza de ingreso de nuevas creencias a las propias comunidades.

Ahora bien, aunque la experiencia de quienes eligen otra opción religiosa a partir de la migración siempre ha estado presente en la historia de la migración mexicana hacia los Estados Unidos, ${ }^{17}$ en ocasiones se le ha magnificado, sobredimensionándose el impacto -real- que pudiera tener en las comunidades de origen en el sentido de la exportación y el desarrollo de otras opciones religiosas. Esto probablemente se debe a que los casos de conversión, además de ser muy significativos, son también fenómenos que adquieren una gran visibilidad por la confrontación que conlleva el cuestionamiento de la universalidad de prácticas, normas y valores de las comunidades de origen. De tal suerte, en no pocas ocasiones esos procesos de conversión han sido detonadores de tensiones y conflictos al interior de las comunidades. ${ }^{18}$

Así pues, es necesario relativizar el impacto de la migración en los procesos de conversión en al menos dos sentidos. Por una parte, aunque en definitiva la exposición a la diversidad religiosa, el distanciamiento de mecanismos de control tradicionales y la vulnerabilidad de los migrantes contribuyen a construir un contexto favorable para el cambio religioso, ello de ninguna manera significa que tales elementos sean suficientes para que esos procesos tengan lugar. Y, por otra parte, es también necesario identificar hasta qué punto este factor de cambio religioso resulta significativo para comprender la diversificación de las opciones religiosas en el ámbito nacional.

Aunque es imposible saber con precisión qué proporción de quienes migran “abandonan la fe de sus abuelos”, trabajos recientes permiten tener una imagen aproximada de esos procesos. ${ }^{19}$ Así, por ejemplo, Gastón Espinosa y Virgilio Elizondo

${ }^{17}$ Ya en 1930, Manuel Gamio sostenía, en su trabajo pionero sobre la migración mexicana hacia los Estados Unidos, que una vez que el migrante cruza la frontera, en donde "the Protestant propaganda brings to him attention the weak points of the Catholic church [...] one of three things happens: he becomes a normal, non-fanatic Catholic; indifferent or an unbeliever; or a Protestant" (Gamio, 1971).

${ }^{18}$ Este aspecto será retomado más adelante.

19 Conviene insistir en que, debido a que el Censo de los Estados Unidos no proporciona información relativa a la adscripción religiosa, los datos existentes para ese país provienen de encuestas telefónicas diversas. La metodología empleada por Espinosa y Elizondo puede ser consultada en la página electrónica del Institute for Latino Studies de la Universidad de Notre Dame (www.nd.edu/\%7Elatino/research/ publications.htm). 
(2003) encontraron que al menos 70\% de los "latinos" 20 que viven en los Estados Unidos se consideran católicos. Estos datos, sin embargo, varían de una generación a otra: en la generación que emigró, el catolicismo asciende al menos a $74 \%$, pero en la generación de sus hijos desciende a 72\%, llegando a aproximadamente $62 \%$ para la tercera generación. Simultáneamente, la adscripción al protestantismo pasa de poco menos de $15 \%$ en la generación migrante, a $20 \%$ en la segunda generación, y a casi $29 \%$ en la tercera. ${ }^{21}$ A pesar de ese proceso de cambio, el porcentaje de latinos católicos parece mantenerse relativamente estable, en $70 \%$, debido a que nuevos migrantes católicos ingresan constantemente a ese contingente.

En lo que respecta a la magnitud del impacto de tales procesos de conversión en las comunidades de origen, se pueden encontrar también algunas aproximaciones a partir de las fuentes estadísticas disponibles. Podemos observar en primera instancia que los estados mexicanos donde la adscripción al catolicismo ha caído de manera más acelerada, no han tenido una participación significativa en los flujos migratorios. De igual manera, aquellos estados con mayor participación migratoria hacia los Estados Unidos son los que presentan una adscripción al catolicismo cercana a $100 \%$.

La representación cartográfica de esos mismos indicadores, como se muestra en los mapas I y II, permite identificar con claridad que el cambio religioso se relaciona antes con procesos regionales que con la intensidad de la migración hacia los Estados Unidos. ${ }^{22}$ Así, comparando la distribución espacial de los índices de intensidad migratoria, y la distribución espacial del crecimiento

${ }^{20}$ Esta categoría incluye a todas las personas nacidas en América Latina o de origen latinoamericano, y no solamente a los mexicanos. Aunque estos últimos constituyen un porcentaje muy importante de los "latinos" o "hispanos", las cifras aportadas deben tomarse con prudencia, pues otros contingentes migratorios, en particular los provenientes de América Central, presentan una mucho más elevada participación en opciones religiosas no católicas.

${ }^{21}$ Resulta interesante la observación de Espinosa y Elizondo, quienes resaltan que debido a la magnitud de la población "latina" de los Estados Unidos, "there are now more Latino Protestants in the United States, than Jews or Muslims or Episcopalians and Presbyterians combined" (Espinosa y Elizondo, 2003).

22 José Luis Molina presenta una regionalización similar a la que aquí exponemos, basada en las transformaciones del campo religioso, en donde distingue tres regiones principales: el centro-occidente, que presenta la adscripción al catolicismo más elevada; la región sur-sureste, que corresponde a la mayor presencia de religiones diferentes del catolicismo, y la frontera norte, que se ubicaría entre las dos anteriores (Molina Hernández, 2003). La región centro-occidente coincide con la de mayor intensidad migratoria, seguida por la frontera norte. La región sur-sureste es precisamente aquella en donde la intensidad migratoria es más baja o nula. 


\section{Mapa I \\ Población no católica por entidad federativa (2000)}

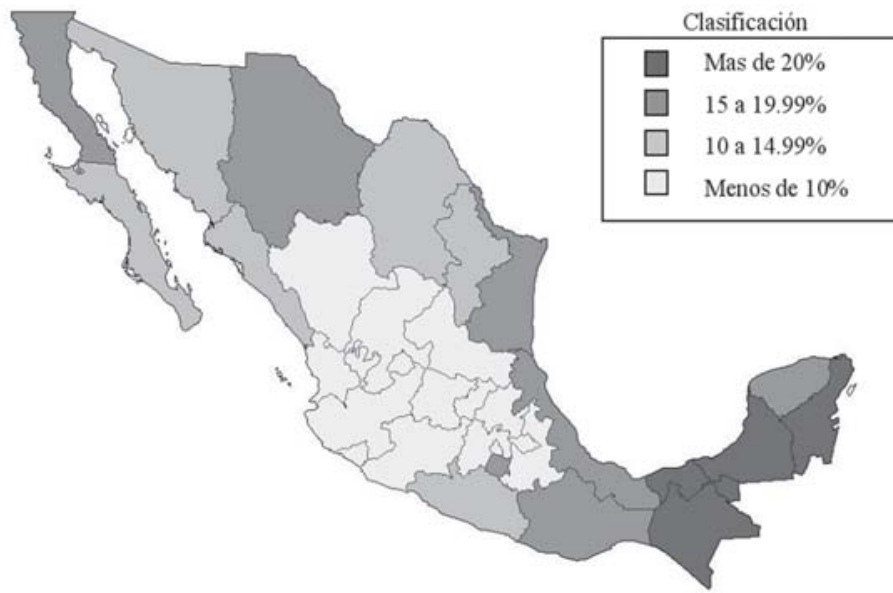

Fuente: XII Censo General de Población y Vivienda 2000. Elaboración de Manuel Tapia.

\section{Mapa II}

Participación en la migración internacional (Índice de Intensidad Migratoria, 2000)

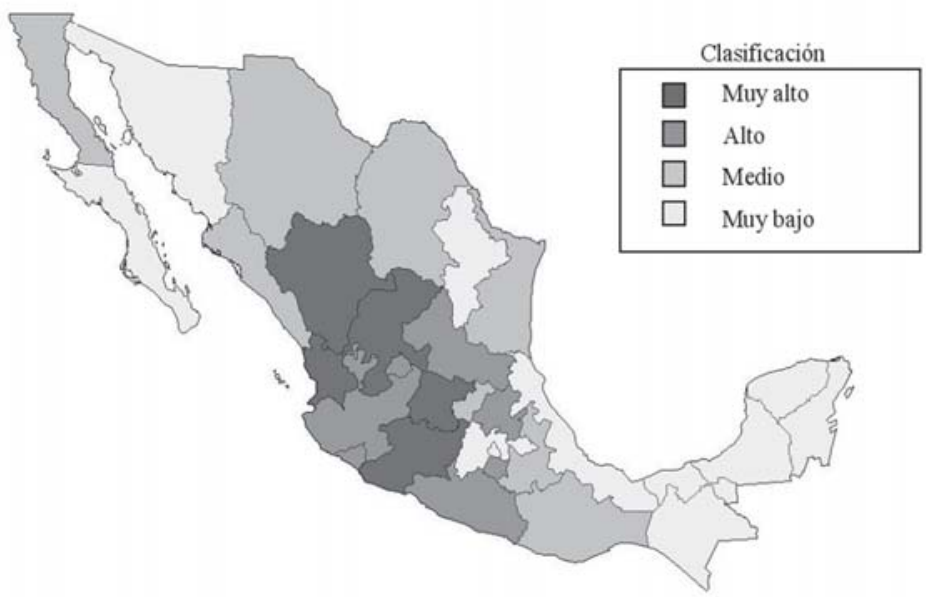

Fuente: Tuirán et al. (2002). Elaboración de Manuel Tapia. 
de opciones religiosas distintas al catolicismo, podemos observar que es precisamente la región que tradicionalmente ha enviado los mayores contingentes de migrantes hacia los Estados Unidos, la que hasta la fecha es el "bastión" del catolicismo en México. Simultáneamente, el sureste del país, que concentra los procesos de cambio más marcados -con un decrecimiento de la adscripción al catolicismo de hasta 33 puntos porcentuales en cinco décadas-, ha estado prácticamente ausente del éxodo hacia el norte.

Hay, por supuesto, algunas excepciones interesantes, como los estados de Oaxaca o Morelos, que a pesar de no contar con una "historia migratoria" de tan larga data como los estados del centro-occidente, en las últimas décadas se han incorporado masivamente al contingente de trabajadores transnacionales. Los indicadores de "intensidad migratoria" (Tuirán et al., 2002) los ubican en la actualidad entre los estados con una alta participación en los flujos migratorios, y presentan también porcentajes de adscripción al catolicismo (84.8 y 83.6, respectivamente) notablemente inferiores a la media nacional (88\%).

Para tratar de identificar de manera más precisa aquellos lugares en donde pudiera coincidir una importante participación en la migración internacional y el cambio religioso, representamos gráficamente la relación entre porcentaje de población no católica e índice de intensidad migratoria para cada municipio mexicano (gráfica IV).

Como se puede observar, con excepción de una decena de casos -los más sobresalientes se ubican en el estado de Oaxaca- ${ }^{23}$ los municipios que presentan índices de migración elevados corresponden con aquellos que presentan también un alto porcentaje de adscripción al catolicismo, mientras que aquellos con una diversidad religiosa más acentuada tienen los índices de intensidad migratoria más bajos.

¿Significa esto que la migración no constituye un factor de cambio religioso importante? Seguramente no. La evidencia empírica muestra que la experiencia migratoria es fundamental para comprender la trayectoria de los migrantes conversos; sin embargo, la transformación del campo religioso mexicano presenta características regionales diferenciadas, que no pueden reducirse a los cambios de adscripción religiosa y que no se circunscri-

${ }^{23}$ Las tres excepciones más notables las constituyen los municipios oaxaqueños de San Juan Numí, San Mateo Cajonos y Nuevo Zoquiapam, que presentan altos índices de intensidad migratoria, además de acelerados procesos de cambio religioso. Estos tres casos, sin duda, ameritarían un estudio aparte. 


\section{Gráfica 4}

Diversidad religiosa e intensidad migratoria (municipios, 2000)

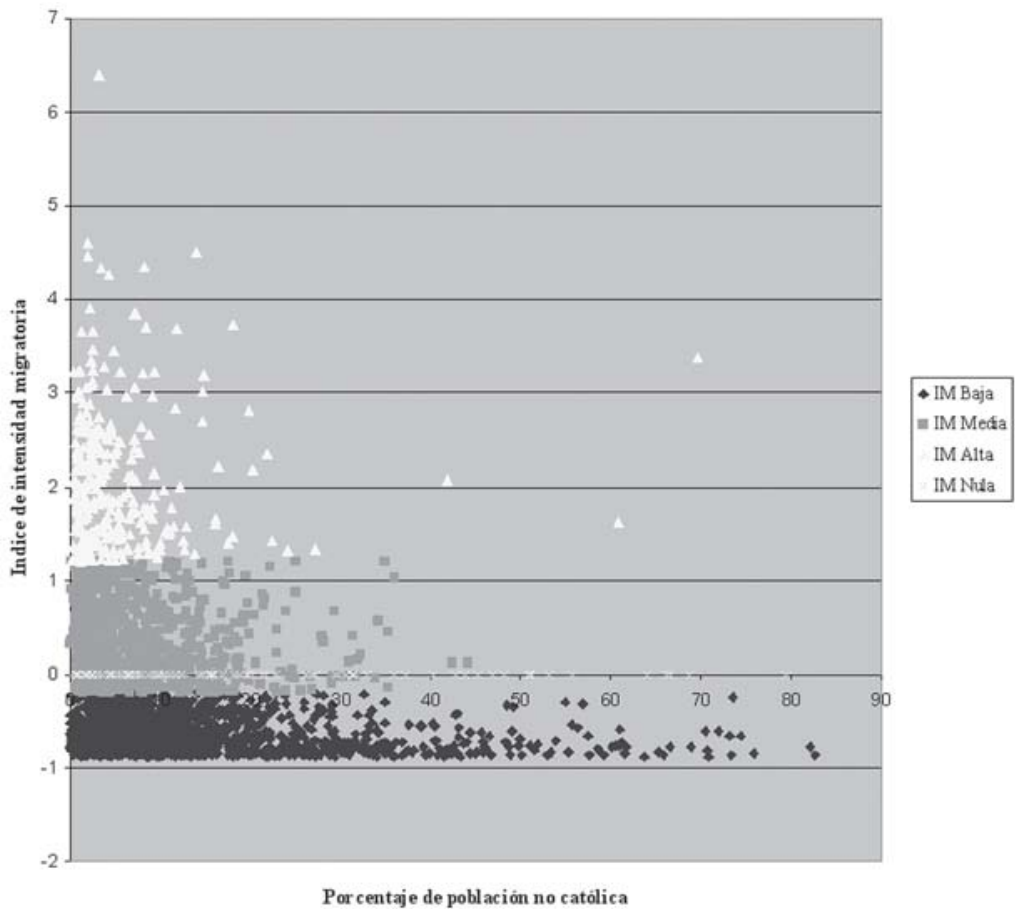

Fuente: Elaboración propia con base en los censos y el índice de intensidad migratoria del Conapo.

ben a las regiones con más alta intensidad migratoria. ${ }^{24} \mathrm{~A}$ pesar de ello, existen algunas regiones en donde la migración, en combinación con otras variables históricas y sociodemográficas, sigue siendo una pista de investigación relevante en la comprensión de los procesos de diversificación religiosa.

\section{La transnacionalización de las prácticas religiosas}

La religión, entendida como un sistema de creencias que permiten a los individuos conferir un sentido a su experiencia cotidiana, a su pasado y a su porvenir, debe forzosamente adaptarse a las nuevas condiciones de existencia de quien la profesa, a la reconstrucción de sus orígenes y a sus nuevas expectativas para

${ }^{24}$ Diversos estudios han analizado las transformaciones en el panorama religioso del sureste mexicano -en donde la migración no constituye un factor de cambio significativo. Véanse, entre otros, Garma (2002) y Rivera (1998). 
el porvenir. ${ }^{25}$ La religión, como sistema de creencias, pero también en su dimensión ritual, de ética normativa y como referente de identidad colectiva, debe ser reinterpretada también para conferir un sentido a las nuevas carencias e incertidumbres y así poder constituir un recurso de orientación práctica.

En particular, para que los sistemas religiosos movilizados por los migrantes sigan respondiendo a las necesidades individuales y sociales de producción de sentido, deben adecuarse a una experiencia de vida que se desarrolla en un campo social transnacional (cf. Levitt y Glick-Schiller, 2004).

Y si bien es cierto que las instituciones religiosas, como la Iglesia católica, han operado siempre como instituciones supranacionales, los sistemas religiosos pretendidamente universales se han adecuado en cada ocasión a los contextos locales, en donde deben cristalizar en ritos y normas específicos (Kurtz, 1995). Así pues, a pesar de la visión supranacional de la organización católica, podemos identificar un "catolicismo a la mexicana" -en donde destacaría por ejemplo la devoción a la Virgen de Guadalupe- que se declinaría a su vez en diversas formas de "ser católico" en lo regional, lo local y lo individual.

Por consiguiente, la adecuación del catolicismo a la experiencia de vida en espacios transnacionales ${ }^{26}$ no significa la sustitución de una forma "local" de ser católico por otra supranacional. Los sistemas religiosos con los que viajan los migrantes, para perdurar, deben ser susceptibles de cristalizar en orientaciones prácticas que respondan a las incertidumbres que la vida cotidiana impone a los individuos. Así, el catolicismo de las comunidades de origen de los migrantes debe readecuarse de forma tal

${ }^{25}$ El problema de la definición de lo que es -o no es- "religión" ha estado presente a lo largo de la historia de la sociología de las religiones. No obstante, tanto en los enfoques "sustancialistas" como en los basados en las "funciones" de los sistemas religiosos, existe el acuerdo en la relevancia de esos sistemas de creencias como portadores de "sentido". En este trabajo, asumiendo que la definición es un asunto problemático, de manera operativa consideramos que como “'representaciones religiosas” se engloba al conjunto de las construcciones imaginarias mediante las que la sociedad, los grupos en esta sociedad, y los individuos en estos grupos tratan de conferir un sentido a su experiencia cotidiana y representarse su origen y su porvenir" (Hervieu-Léger, 1996). Desde esta posición, entendemos al creyente como sujeto social que interpreta y transforma el sistema de creencias y la normatividad que de éste se deriva.

Esta definición preliminar es complementada con las aportaciones de otros autores, entre ellos: Campiche (2003), Cipriani (2004), Hervieu-Léger (1993), Hirschman (2004), Kurtz (1995), Randaxhe (2003), Varguez Pasos (2001), y Warner (1993), que son citados en cada caso.

${ }^{26}$ Tomamos este término, y el desafío teórico-metodológico implícito, del trabajo de Levitt y Glick-Schiller (2004: 11). 
que siga siendo "portador de sentido" para quienes viven su cotidianidad en espacios transnacionales.

Con esta perspectiva podemos entender mejor la relevancia que algunas prácticas religiosas específicas han adquirido entre algunas "comunidades transnacionales", que han logrado recrear nuevas formas de definición del "nosotros" prescindiendo de los referentes de adscripción a un Estado nacional -o relativizándolos- y confiriendo el núcleo de la identidad comunitaria a la adscripción a un referente religioso. El caso más evidente, aunque sin duda no el único, es la relevancia que han adquirido las devociones a los santos patronos de las comunidades de origen. La devoción -íntima- al santo permite al individuo revitalizar los lazos de identidad con sus paisanos en donde quiera que se encuentre, y revitalizar también los nexos con sus antepasados. Las celebraciones religiosas realizadas en las comunidades de destino posibilitan la construcción de nuevos vínculos con los paisanos en el terruño. La participación de los migrantes en las celebraciones que se realizan en los lugares de origen -ya sea una participación "virtual” por el envío de dólares y "promesas", o por medio de la celebración simultánea del festejo en el lugar de destino- permite crear nuevos puentes y revitalizar identidades con quienes quedaron atrás, identificándose como "hijos de un mismo Padre" (Varguez Pasos, 2001). ${ }^{27}$ La transmisión de la devoción a los hijos nacidos en los Estados Unidos hace también posible la incorporación de las siguientes generaciones a esa forma particular de redefinir las identidades colectivas.

De esta manera, lejos de tratarse de una simple "exportación" de prácticas religiosas locales, esas formas específicas de devoción reflejan la construcción de prácticas religiosas transnacionales capaces de estructurar una nueva identidad colectiva, aportando así nuevos sentidos a una existencia cotidiana transnacional. Ese tipo de celebraciones muestra, también, la forma como los referentes religiosos resignificados en el espacio social transnacional pueden aportar orientaciones prácticas que señalan a los individuos lo que la comunidad -en sus múltiples localizacionesespera de ellos, así como elementos para redefinirse en el contexto multiétnico y multirreligioso de la sociedad de destino.

\footnotetext{
27 En el trabajo citado, Varguez propone que "a diferencia de las identidades de origen, de género, étnicas o laborales, las metaidentidades religiosas son construidas a partir de las relaciones que el creyente establece con la divinidad y sus representaciones, y del sentimiento de pertenencia a una comunidad cuyos integrantes se reconocen como hermanos por ser hijos de un mismo Padre y una misma Madre" (Varguez Pasos, 2001).
} 
Existe ya una abundante literatura en donde se detalla el proceso de construcción de esas prácticas religiosas transnacionales asociadas con la devoción a santos patronos locales. ${ }^{28}$ Hay, sin embargo, dos ejemplos que nos parecen particularmente ilustrativos de la readecuación de las prácticas religiosas a las nuevas necesidades espirituales -o de aportación de sentido- de las comunidades transnacionales. La primera es la resignificación de los santos patronos como "santos migrantes". La segunda, que puede ser paralela a la anterior, es la especialización de los mismos como santos protectores de migrantes.

El primer caso puede verse nítidamente representado en el Padre Jesús, santo patrono de Chinantla, Puebla. Juan Gómez, chinantleco que reside en Nueva York desde 1989, narró lo que sucedió en su pueblo hace algún tiempo: durante una peregrinación tradicional, un santo de la región, el Padre Jesús, fue recibido en Chinantla por los mejores músicos del lugar, quienes cantaron con tanto sentimiento que conmovieron al mismísimo santo. Al llegar la hora de partir, cuando los fieles quisieron llevar de regreso a casa a la estatua del santo, ésta pesaba tanto que nadie logró moverla. Después de muchos esfuerzos, la gente comprendió que el santo había decidido emigrar, como durante décadas lo han hecho tantos hombres y mujeres del lugar (Juan Gómez, entrevistado en Nueva York en 1999). ${ }^{29}$ Desde ese día, las personas que han salido de la región para probar su suerte al norte de la frontera regresan cada año, en enero, para recordar el milagro y para adorar al santo migrante. Aseguran que quienes se encomiendan al Padre Jesús, cruzan con bien la frontera "aunque no traigan papeles", y únicamente tienen contratiempos quienes hicieron una promesa al santo y no la cumplieron. Así, el milagro del Padre Jesús contribuyó a transformar la representación social de la migración entre la gente del pueblo, otorgando un aura de legitimidad a los desplazamientos de todas aquellas personas que parten hacia el norte. En definitiva, la nueva práctica religiosa se convirtió en un rito anual de justificación de la migración hacia el norte.

${ }^{28}$ Como es natural, esos procesos no están libres de conflictos y tensiones. Algunos de ellos serán señalados más adelante.

${ }^{29}$ Obviamente, la veracidad de la anécdota narrada por el señor Gómez es irrelevante -de hecho, después de una investigación específica en la región, sabemos que la llegada del santo al pueblo no coincide con esta narración. Lo que es verdaderamente significativo es que la resignificación del Padre Jesús como santo migrante responde a las necesidades de sentido de los oriundos de ese lugar. 
El segundo caso, que nos parece igualmente significativo, es el surgimiento de santos protectores de migrantes en lugares estratégicos del recorrido hacia el norte. Este caso queda bien ejemplificado con Juan Soldado, santo fronterizo no reconocido oficialmente por la Iglesia católica, pero objeto de veneración por varias generaciones de migrantes. Según la historia popular (Ungerleider, 1999), a principios del siglo pasado el soldado Juan fue asesinado, en la ciudad de Tijuana, acusado de un crimen que no cometió. Al descubrirse más tarde que se había castigado a un inocente, los residentes del lugar comenzaron a encender veladoras para el "ánima sola” del soldado Juan, quien encontró una muerte violenta, lejos de su tierra y de sus seres queridos, a pesar de haber sido inocente.

La devoción a Juan Soldado, sin embargo, no adquirió importancia sino hasta las ultimas décadas del siglo xx, cuando Tijuana se constituyó como el principal punto de cruce fronterizo de un vasto flujo migratorio indocumentado. La tumba de Juan Soldado, que se ubica a sólo unos metros de la frontera México-Estados Unidos, se convirtió entonces en la visita obligada de cientos de migrantes que se encomendaban al soldado para lograr llegar con bien hasta "el otro lado". El santo se convirtió así en un protector de migrantes, y en su capilla podían verse infinidad de mensajes de agradecimiento, por haber logrado "obtener un permiso de trabajo", "cruzar sin ser visto por la Patrulla Fronteriza", "haber logrado llevar a la esposa y los hijos 'al otro lado', etc. Recientemente, debido al recrudecimiento de los controles fronterizos en esa región, el flujo migratorio ha debido trasladarse hacia el este, de manera que no son ya tan numerosos los nuevos migrantes que se encomiendan al soldado. Sin embargo, Juan Soldado sigue siendo una figura central de veneración para varias generaciones de migrantes y sus hijos nacidos en los Estados Unidos, quienes siguen realizando peregrinaciones -ahora cruzando la frontera hacia el sur- para encomendarse y agradecer nuevos milagros. Independientemente de la veracidad de los "milagros" atribuidos, es incuestionable que Juan Soldado logró confortar a cientos de personas en un momento de gran angustia -liminal en más de un sentido-, constituyendo un recurso emocional para quienes debieron arriesgar la vida en el cruce.

Tanto el caso del Padre Jesús como el de Juan Soldado constituyen ejemplos de la forma como, aun dentro del catolicismo, la migración ejerce un impacto profundo en los sistemas religiosos, y que lejos de limitarse a la exportación más o menos visible de 
las prácticas religiosas tradicionales, debe readecuarse a nuevas condiciones de vida cotidiana, y por consiguiente a nuevas demandas de sentido y de orientaciones prácticas.

Dentro de este proceso, la relevancia de las religiones en la conformación de nuevos referentes de identidad constituye un punto que nos parece de la mayor importancia. Este aspecto lo trataremos en el siguiente apartado.

\section{La etnicización de las identidades religiosas: migración e (in)tolerancia religiosa}

Como se mencionó anteriormente, la experiencia de la migración hacia los Estados Unidos, y más específicamente, la experiencia de vida en un espacio social transnacional, exige al individuo que se desplaza -y con frecuencia también a quienes permanecen- la reelaboración de referentes identitarios. Ese proceso exige tanto la reconfiguración de la representación del "nosotros", como la redefinición de la alteridad.

En este sentido, uno de los impactos que se pueden observar en el ámbito de las religiones es, precisamente, la transformación de la percepción de la diversidad religiosa.

Según Charles Hirschman (2004), una de las características más comunes en el proceso de "americanización" de las comunidades de inmigrantes es, precisamente, la fundación de una iglesia o templo. En el caso de los mexicanos inmigrantes, ese proceso resulta paradójicamente más difícil debido a que, a pesar de que hay parroquias católicas en sus lugares de destino, encuentran que en ese contexto no existe el espacio necesario para la reproducción de algunas de las prácticas del catolicismo popular que resultan significativas para ellos. Es probablemente por ello que, más que la fundación de una nueva iglesia, en el caso de los migrantes mexicanos con frecuencia se establecen tensiones al interior de las propias iglesias católicas, que en ocasiones van siendo "reconquistadas" por medio de la instauración de algunos servicios en español, la aparición de nuevas imágenes de devoción, etc. (cf. Morán, 2005).

Ello produce en ocasiones una cierta segregación al interior mismo de la comunidad católica, y el sentimiento de formar parte de una minoría dentro del propio catolicismo. ${ }^{30}$ La etniciza-

${ }^{30}$ Diversos autores han mostrado que, en ocasiones, la creación de una iglesia "mexicana" se deriva de la progresiva "colonización" de la iglesia católica local, que se realiza de manera simultánea a la etnicización del barrio en cuestión (cf. Morán, 2005). 
ción de la adscripción religiosa es entonces un elemento adicional que los migrantes católicos deberán enfrentar.

El festejo al santo patrono o las fiestas de XV años pueden tener un sinnúmero de semejanzas externas con esas mismas celebraciones realizadas en el lugar de origen. Su significado, no obstante, suele presentar diferencias sutiles pero importantes: si en el lugar de origen esas celebraciones ubican a quienes las practican dentro de una tradición mayoritaria y hegemónica, en los lugares de destino las mismas celebraciones significan la visibilización de los practicantes como un grupo minoritario y, en ocasiones, estigmatizado. Si antes de migrar esas tradiciones eran esperadas por el resto de la comunidad, en los nuevos contextos implican la decisión de identificarse con un subgrupo dentro de la propia tradición católica, y significa también tejer o consolidar puentes con las comunidades de destino. Esas prácticas significan a la vez un esfuerzo de reivindicación identitaria frente a lo "otro", y un esfuerzo de acercamiento hacia lo propio.

Así, el proceso de etnicización de las expresiones religiosas va cristalizando en diversos espacios, como las propias iglesias católicas, en donde algunas políticas adoptadas a nombre de la tolerancia a la diferencia -como la celebración de misas en varios idiomas- tienen como una de sus consecuencias inmediatas la reproducción de sistemas de segregación -al constituirse grupos diferenciados a partir de los horarios establecidos para las misas en cada idioma.

No es de sorprender, entonces, que dentro de ese contexto de etnicización de las creencias y las prácticas religiosas, los propios migrantes mexicanos perciban la diversidad religiosa de los Estados Unidos como una consecuencia "natural” de la migración. Resulta "natural" -y por consiguiente es respetado- el hecho de que cada grupo étnico profese su religión de origen. Muchos de los migrantes católicos que entrevistamos tenían amistades que profesaban otras religiones, algunos habían asistido en alguna ocasión a ceremonias religiosas de otros grupos étnicos/religiosos, e incluso se expresaban positivamente de algunas de esas tradiciones. Así, por ejemplo, la señora Gilda explica:

Siempre quiere uno estar con los suyos [...] porque siempre recuerda con melancolía de dónde viniste y quiere uno rehacer su colonia en el país extraño [...] pero al mismo tiempo me he dado cuenta que entre más diversidad hay y entre más cosas diferentes, más aprende uno y es más bonito porque ellos transmiten y te enseñan algo de lo que traen (entrevista realizada en Chula Vista, 2003). 
No obstante, esa aparente apertura hacia las religiones de los "otros" contrastaba con la acentuada intolerancia hacia aquellos mexicanos que habían decidido cambiar de religión. En estos casos, además de considerarse que la conversión obedece a intereses materiales, implícitamente lo que se les reprocha más fehacientemente es el haber traicionado la lealtad al grupo étnico y el haber roto los lazos a partir de los cuales se construye la solidaridad grupal. ${ }^{31}$ Es precisamente la experiencia de la diversidad religiosa el factor que impulsa una mayor intolerancia hacia los propios mexicanos no católicos en los lugares de destino. En ocasiones, ese fenómeno resulta aún más evidente cuando los migrantes regresan a las comunidades de origen; encontramos también respuestas distintas e incluso opuestas.

En el caso de los migrantes originarios de Chinantla, encontramos que en algunos casos, como era de esperarse, la representación de la diversidad religiosa como producto de la diversidad étnica era aplicada también a su regreso a casa. Esa reproducción de una visión etnicizada de las identidades religiosas redundaba en un incremento de la intolerancia hacia quienes profesaban religiones diferentes a la católica. En el caso específico de Chinantla, esa situación adquiría dimensiones mayores debido al notorio incremento en el poder político y económico que habían adquirido los migrantes. Así, por ejemplo, la señora Trinidad -Testigo de Jehová- menciona que la organización de la fiesta al santo patrono es una fuente creciente de conflictos entre los comités organizadores -radicados en gran medida en Nueva York- y quienes radican en el pueblo pero no profesan la religión católica. Los comités detentan una capacidad de influencia notable debido a que una parte importante de los ingresos del pueblo proviene de las remesas. Incluso una parte significativa de los recursos administrados por el Ayuntamiento para el mejoramiento de la infraestructura de la cabecera municipal proviene de las remesas colectivas. Por ello, las actitudes más tolerantes de la propia jerarquía católica y de las autoridades civiles resultaban frecuentemente rebasadas por las posturas más inflexibles de los comités. ${ }^{32}$

31 “[los mexicanos cambian de religión] muchas veces por conveniencia; yo he conocido a personas de mi comunidad que han cambiado y dicen que allá dan canastas de navidad [...] sí cambian muchas personas pero más que nada porque no traen sus convicciones firmes, sus creencias, porque no traen la fuerza, o por debilidad, o muchas veces por soledad" (señora Gilda, entrevistada en Chula Vista en 2003).

${ }^{32}$ La señora Trinidad narra que cuando su cuñado se "bautizó" (Testigo de Jehová), los organizadores de la fiesta le dijeron que tenía que ir con el grupo de hombres que iban a pintar la iglesia. El cuñado de la señora Trinidad se negó argumentando que su 
Algunos de los migrantes que viajan a Chinantla para la fiesta patronal dicen con orgullo a sus hijos -nacidos en los Estados Unidos- que a diferencia de lo que sucede en los Estados Unidos, en el pueblo no hay lugar para otras religiones. Al parecer, ante sus ojos el pueblo perdería su pureza original si otras religiones comenzaran a expandirse. Así, por ejemplo, el señor Javier, quien vive en Nueva York desde 1960 y regresa regularmente -ahora con sus hijos y nietos- a la fiesta del Padre Jesús, comenta: "Allá en Nueva York sí llegan [a tocar la puerta] y dicen: 'mire, somos Adventistas' y así, [...pero] aquí no, [...] aquí nos les ponemos al brinco, no porque no; y es que si tienes algo tú en tu mente, es lo que te enseñaron tus padres, y eso no se te quita, nadie te lo puede quitar... voluntariamente no" (entrevista realizada en Chinantla, enero de 2003). Esa postura es compartida incluso por quienes aseguran tener amigos -de otras nacionalidades- que profesan religiones diferentes al catolicismo: nuevamente la diversidad religiosa es tolerada, e incluso valorada, siempre y cuando se manifieste en "los otros" y lejos de casa.

En suma, aunque la respuesta de los migrantes mexicanos a la confrontación con una mayor diversidad religiosa es muy variable, es posible distinguir algunos rasgos relevantes. Probablemente una de las transformaciones más significativas que se derivan de la experiencia de la migración hacia un contexto en donde prevalece una marcada diversidad religiosa -diversidad que adquiere una gran visibilidad en el espacio público-, es la construcción y exportación de una representación de la diversidad religiosa como un reflejo de la diversidad étnica.

Las prácticas religiosas asociadas con una identidad nacional/ local se convierten en instrumentos privilegiados para reestructurar relaciones de paisanaje en los lugares de destino, construir o reforzar redes de solidaridad, y crear espacios favorables a la redefinición de referentes de identidad. Asimismo, esas prácticas religiosas etnicizadas y resignificadas constituyen valiosísimas herramientas para redefinir nexos con las comunidades de origen.

De esta forma, la etnicización de los referentes religiosos permite a un segmento de la población mexicana migrante la construcción de una trinchera identitaria (Odgers Ortiz, 2002) que puede

religión no se lo permitía, y propuso dar una contribución económica a cambio; sin embargo, los miembros del comité organizador no aceptaron y solicitaron al presidente municipal que encarcelara al "revoltoso". La señora Trinidad asegura que las autoridades cedieron a la presión y su cuñado fue encarcelado momentáneamente (entrevista realizada en Chinantla en enero de 2003). 
resultar de gran utilidad ante un contexto de discriminación. Paradójicamente, esa nueva herramienta, construida para reivindicar la diferencia cultural, se convierte en un vector de intolerancia hacia el interior de la propia comunidad de referencia.

Más aún, la nueva percepción de la diversidad en ocasiones es exportada a las comunidades de origen, magnificada por la relación de poder asimétrica que se establece entre quienes migran y quienes permanecen. La intolerancia "importada" a las comunidades de origen parece ser mayor, precisamente, entre quienes sufren la discriminación de manera más directa, y no necesariamente corresponde a quienes antes de migrar participan de manera más activa en las iglesias católicas locales.

\section{Para concluir: hacia nuevos estudios sobre la relación migración-cambio religioso}

La experiencia de los mexicanos que migran hacia los Estados Unidos -y de regreso- permite observar con claridad que existe una importante relación entre la experiencia del desplazamiento y algunas transformaciones en las prácticas y creencias religiosas. Esta relación, no obstante, es extraordinariamente heterogénea, por lo que es difícil identificar patrones o tendencias generales: el mismo factor -la experiencia migratoria- puede producir efectos diferentes e incluso diametralmente opuestos -conversión religiosa o revitalización de prácticas tradicionales, por ejemplo- en regiones distintas.

El contacto con otras opciones religiosas, el distanciamiento de mecanismos de control social y, sobre todo, la flexibilidad y capacidad de adaptación que la condición de migrante exige, resultan factores determinantes en el proceso de reelaboración de la relación que el individuo establecerá con las iglesias y "las creencias de sus abuelos”. Sin embargo, los caminos que ese proceso puede seguir son extremadamente variados y de ninguna manera pueden circunscribirse a los procesos de conversión religiosa. Por ello, el análisis del impacto de la migración en el cambio religioso deja abiertos diversos posibles itinerarios de investigación.

Así, por ejemplo, convendría explorar en que forma particular $-\mathrm{y}$ con qué consecuencias- se manifiestan los procesos de individualización de las creencias, que han sido considerados como una característica fundamental de la modernidad religiosa. Asimismo, convendría reflexionar sobre las implicaciones de la vitalidad de las prácticas religiosas de comunidades transna- 
cionales, que parecen ir justamente a contracorriente de los procesos de individualización.

Seguramente en la medida en que se continúe el análisis del impacto de la migración en las formas de creer, a partir de sus expresiones concretas, podremos aproximarnos a una mejor comprensión de las tendencias globales del cambio religioso, y a un mejor entendimiento de las condiciones y necesidades -emocionales o "espirituales"- de quienes viven en contextos sociales transnacionales, así como de las respuestas que han ido construyendo a lo largo de los años. Esperamos que este trabajo contribuya en esa dirección.

\section{Bibliografía}

Bastian, Jean-Pierre (1994), Protestantismos y modernidad latinoamericana. Historia de unas minorías religiosas activas en América Latina, Fondo de Cultura Económica, México.

Campiche, Roland (2003), "L'individualisation constitue-t-elle encore le paradigme de la religion en modernité tardive?", Social Compass, 50 (3): 297-309.

Cipriani, Roberto (2004), Manual de sociología de la religión, trad. V. Roldán, Siglo xxi Editores, Buenos Aires.

Espinosa, Gastón y Virgilio Elizondo (2003), "Hispanic Churches in American Public Life: Summery of Findings", Interim Reports, University of Notre Dame, Notre Dame.

Espinoza, Víctor M. (1999), "El día del emigrante y el retorno del purgatorio: Iglesia, migración a los Estados Unidos y cambio sociocultural en un pueblo de Los Altos de Jalisco", Estudios Sociológicos, XVII (50): 375-418.

Gamio, Manuel (1971), Mexican Immigration to the United States. A Study of Human Migration and Adjustment, Dover Publications, Nueva York [1 $1^{\text {a }}$ edición 1930, University of Chicago Press].

Garma Navaro, Carlos (2002), "Religious Affiliation and Conflict in the Indian Municipalities of Chiapas”, Social Compass, 49 (1): 29-40. 
Hamberg, Eva M. (1999), "International Migration and Religious Change", en U. R. Görman (ed.), Towards a New Understanding of Conversion, Teologiska Institutionen Religio, 50 , Lund.

Hernández Madrid, Miguel (2000), "El proceso de convertirse en creyente”, Relaciones, xxI (83), 67-98.

(2003), "Diversificación religiosa y migración en Michoacán”, en Gustavo López-Castro, Diáspora michoacana, El Colegio de Michoacán-Gobierno del Estado de Michoacán, Zamora, pp. 165-192.

Hervieu-Léger, Danièle (1993), La religion pour mémoire, Cerf, París.

(1996), "Por una sociología de las nuevas formas de religiosidad: algunas cuestiones teóricas previas", en G. Giménez, Identidades religiosas y sociales en México, IFAL-IIS, unam, México, pp. 23-46.

(1999), Le pèlerin et le converti, Flammarion, Francia.

Hirschman, Charles (2004), "The Role of Religion in the Origins and Adaptation of Immigrant Groups in the United States”, International Migration Review XXXVIII (3): 1206-1233.

Kurtz, Lester (1995), Gods in the Global Village. The World's Religions in Sociological Perspective, Pine Forge Press, Thousand Oaks.

Levitt, Peggy y Nina Glick-Schiller (2004), “Conceptualizing Simultaneity: A Transnational Social Field Perspective on Society", International Migration Review XXXVIII (3): 10021039.

Molina Hernández, José Luis (2003), “Configuración regional del territorio religioso en México", Frontera Norte, 15 (30): 91-119.

Morán, Luis Rodolfo (2000), Barrios mexicanos en Chicago: Delimitaciones étnico-espaciales más allá de las fronteras 
internacionales, comunicación presentada en el congreso La Frontera: una nueva concepción cultural, Mérida.

Odgers Ortiz, Olga (2002), Identités frontalières, Immigrés mexicains aux Etats-Unis, L' Harmattan, París.

— y Renée de la Torre (2004), “Cartografías del cambio religioso en México (1950-2000)", en Cristina Gutiérrez Zúñiga (ed.), El fenómeno religioso en el occidente de México, El Colegio de Jalisco-Universidad de Guadalajara, Guadalajara.

Randaxhe, Fabienne (2003), “De 'l'exception religieuse' etatsunienne”, Archives de Sciences Sociales des Religions, 122.

Rivera, Carolina et al (2005), Diversidad religiosa y conflicto en Chiapas: intereses, utopias y realidades, UNAM-CIESAS, México.

Tuirán, Rodolfo, Carlos Fuentes y José Luis Ávila (2002), Índices de intensidad migratoria México-Estados Unidos, 2000, Consejo Nacional de Población, México.

Ungerleider, David (1999), "La religiosidad popular en Tijuana: la devoción a Juan Soldado", El Bordo: Retos de Frontera, II (4): 89-95.

Varguez Pasos, Luis (2001), Construyendo metaidentidades. Cambio y continuidad en el Movimiento de Renovación Carismática en el Espíritu Santo, comunicación presentada en el congreso XxiII Latin American Studies Association (LASA), Washington D.C.

Warner, Stephen R. (1993), “Work in Progress toward a New Paradigm for the Sociological Study of Religion in the United States", American Journal of Sociology, 98 (5): 1044-1093.

— y Judith Wittner (eds.) (1998), Gatherings in Diaspora. Religious Communities and the New Immigration, Temple University Press, Filadelfia. 
Recibido: 25 de noviembre de 2005. Aceptado: 30 de enero de 2006.

Olga Odgers Ortiz. Doctora en Sociología por la Escuela de Altos Estudios en Ciencias Sociales (París, Francia) en el Centro de Análisis y de Intervención Sociológica. Actualmente se encuentra adscrita al Departamento de Estudios Sociales de El Colegio de la Frontera Norte. Sus líneas de investigación son la migración y cambio religioso. Entre sus publicaciones destacan: "Migración e (In)tolerancia religiosa: aportes al estudio del impacto de la migración internacional en la percepción de la diversidad religiosa” Estudios Fronterizos núm. 12 (2006); "Cambios religiosos en la frontera norte: aportes al estudio de la migración y las relaciones transfronterizas como factores de cambio" Frontera Norte núm. 31, vol. 18 (2006). 